\title{
Corrigendum: Pramel7 mediates ground-state pluripotency through proteasomal-epigenetic combined pathways
}

Urs Graf, Elisa A. Casanova, Sarah Wyck, Damian Dalcher, Marco Gatti, Eva Vollenweider, Michal J. Okoniewski, Fabienne A. Weber, Sameera S. Patel, Marc W. Schmid, Jiwen Li, Jafar Sharif, Guido A. Wanner, Haruhiko Koseki, Jiemin Wong, Pawel Pelczar, Lorenza Penengo, Raffaella Santoro and Paolo Cinelli

Nature Cel/ Biology http://dx.doi.org/10.1038/ncb3554 (2017); published online 12 June 2017; corrected after print 21 June 2017

In the version of this Article originally published, the following affiliation was omitted for Sarah Wyck: Clinic of Reproductive Medicine, University of Zurich, Winterthurerstrasse 260, CH-8057 Zurich, Switzerland. This has been corrected in the online version of the Article.

\section{Corrigendum: Pulsatile cell-autonomous contractility drives compaction in the mouse embryo}

Jean-Léon Maître, Ritsuya Niwayama, Hervé Turlier, François Nédélec and Takashi Hiiragi

Nature Cell Biology 17, 849-855 (2015); published online 15 June 2015; corrected after print 5 July 2017

In the version of this Article originally published, the wave velocity reported in the sentence beginning 'In the absence of cell-cell contacts...' was incorrectly calculated and should have read ' $0.8 \pm 0.1 \mu \mathrm{m} \mathrm{s}^{-1}$ '. The wave velocity is calculated by dividing the cell perimeter by the oscillation period, and further dividing this by two as there are two waves travelling around the cell. The number of waves was not taken into account in the originally published version of the Article. This mistake does not affect the main conclusions of the paper, as this sentence only describes a property of the phenomenon identified. This error has been corrected in the online version of the Article. 